\title{
Dual-chamber epicardial pacing in neonates with congenital heart block
}

\author{
Angela M. Kelle, BS, ${ }^{a, c}$ Carl L. Backer, MD, ${ }^{a, c}$ Sabrina Tsao, MBBS, ${ }^{\text {b,d }}$ Robert D. Stewart, MD, ${ }^{a, c}$ \\ Wayne H. Franklin, MD, ${ }^{\text {,d }}$ Barbara J. Deal, MD, ${ }^{\text {,d }}$ and Constantine Mavroudis, MD ${ }^{a, c}$
}

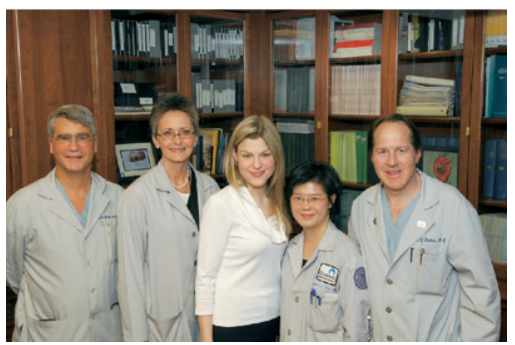

Drs Mavroudis and Deal, Ms Kelle, and Drs Tsao and Backer (left to right)
From the Divisions of Cardiovascular and Thoracic Surgery ${ }^{\mathrm{a}}$ and Cardiology, ${ }^{\mathrm{b}}$ Children's Memorial Hospital, and the Departments of Surgery ${ }^{\mathrm{c}}$ and Pediatrics, ${ }^{\mathrm{d}}$ Northwestern University Feinberg School of Medicine, Chicago, Ill.

Read at the 30th Annual Meeting of the Midwest Pediatric Cardiology Society, Columbus, Ohio, Sept 7-8, 2006

Received for publication March 2, 2007; revisions received April 5, 2007; accepted for publication April 16, 2007.

Address for reprints: Carl L. Backer, MD, Division of Cardiovascular-Thoracic Surgery, M/C \#22, Children's Memorial Hospital, 2300 Children's Plaza, Chicago, IL 60614; (E-mail: cbacker@childrensmemorial.org).

J Thorac Cardiovasc Surg 2007;134:1188-92 $0022-5223 / \$ 32.00$

Copyright $\odot 2007$ by The American Association for Thoracic Surgery

doi:10.1016/j.jtcvs.2007.04.049
Objective: This review evaluates the outcome of a treatment strategy using dualchamber pacemakers for neonates with congenital heart block.

Methods: From 1989 to 2006, 10 neonates had dual-chamber epicardial pacemaker placement for congenital heart block. Mean age and weight were $4.4 \pm 5.6$ days and $2.8 \pm 0.6 \mathrm{~kg}$. Four patients had heterotaxy syndrome and required concomitant cardiac procedures. One patient had fetal hydrops, myocarditis, and cardiomyopathy. Five patients had structurally normal hearts. Sternotomy (2 partial, 8 full) and unipolar leads ( 2 non-steroid eluting, 18 steroid-eluting) were used in all. Generators were placed in submuscular bilateral rectus sheath pockets.

Results: Successful atrioventricular synchrony was established in all patients. Mean P-wave sensing was $4.7 \pm 2.6 \mathrm{mV}$ and atrial voltage threshold was $0.8 \pm 0.3 \mathrm{~V}$. Mean R-wave sensing was $13.0 \pm 5.7 \mathrm{mV}$ and ventricular voltage threshold $0.9 \pm$ $0.5 \mathrm{~V}$. There were no wound complications or acute lead failures. Median postoperative stay was 14 days. Three of the 4 patients with heterotaxy died at 3 days, 14 days, and 15 months postoperatively. The patient with cardiomyopathy died suddenly at 6 months of acute myocarditis. No patient with a structurally normal heart died $(P<.05)$. Mean follow-up interval in survivors is $6.1 \pm 7.1$ years with 1 patient lost to follow-up.

Conclusions: Implantation of a dual-chamber epicardial pacemaker in neonates with congenital heart block is technically feasible and results in excellent outcomes in patients with structurally normal hearts. System longevity at 6 years is excellent. Patients with congenital heart block and heterotaxy syndrome have a poor prognosis despite dual-chamber pacing.

$\mathrm{C}$ ongenital complete heart block ( $\mathrm{CHB})$ is a rare conduction anomaly occurring in $1 / 11,000$ to $1 / 20,000$ live births. ${ }^{1}$ It is defined as atrioventricular block "diagnosed in utero, at birth, or in the first month of life." ${ }^{2}$ Historically, neonates with CHB have been separated into three primary groups. ${ }^{1}$ In the first group, CHB is associated with maternal connective tissue disease. The most common association is with maternal systemic lupus erythematosus. ${ }^{3}$ Maternal antibodies begin circulating through the fetus in the mid-second trimester and affect the myocardium, particularly conducting tissue, leading to fibrous replacement of the tissue. ${ }^{1,4}$ In the second group, heart block is associated with other cardiac defects, most commonly left atrial isomerism; it is thought that discontinuity between the atrioventricular node and the ventricular conduction tissues results in heart block. ${ }^{1}$ Thirty percent of all patients with CHB are in this group. ${ }^{5}$ The third and smallest group, up to $10 \%$, consists of neonates with seronegative isolated CHB. $^{1}$

Previous studies have reported mortality rates for isolated CHB ranging from $11 \%$ to $45 \%{ }^{1}$ Mortality rates for $\mathrm{CHB}$ with heterotaxy syndrome are much higher 


\section{Abbreviations and Acronyms \\ $\mathrm{CHB}=$ congenital heart block \\ $\mathrm{DDD}=$ dual-chamber pacing}

and were reported at $100 \%$ in a recent study from Toronto. ${ }^{6}$ Delayed pacing therapy or hemodynamic compromise from associated cardiac defects results in early death according to most series. $^{7}$

We began implanting single-lead, epicardial ventricular pacemakers for neonatal CHB in 1971, as reported by Idriss and associates in $1973 .{ }^{8}$ Dual-chamber pacemakers were too cumbersome for neonatal use, and atrial leads functioned poorly at that time. However, advances in pacemaker technology (smaller hardware and longer battery life) have allowed the advantages of dual-chamber pacing, such as atrioventricular synchrony and sinus node responsiveness, to outweigh the drawbacks of a larger device and the need for two leads. The use of steroid-eluting epicardial leads allowed for successful atrial lead placement. ${ }^{9}$ We have implanted dual-chamber epicardial pacemakers for $\mathrm{CHB}$ for the past 17 years. The purpose of this review is to evaluate the outcome of that treatment strategy.

\section{Materials and Methods}

The Institutional Review Board at Children's Memorial Hospital, Chicago, Illinois, approved this retrospective study and granted a waiver of informed consent on October 25, 2005.

We identified 10 patients from our computerized cardiovascular database who underwent neonatal surgical implantation of a dual-chamber epicardial pacemaker for CHB between February 1989 and January 2006. There were 4 boys and 6 girls with a mean age of $4.4 \pm 5.6$ days (range 1-19 days) and mean weight of $2.8 \pm$ $0.6 \mathrm{~kg}$ (range $2.0-4.2 \mathrm{~kg}$ ). The medical records of all patients were reviewed. Cardiac diagnosis, operative technique, concomitant cardiac procedures at pacemaker implant, and patient age and status at follow-up were reviewed. Data collected included pacemaker programming data and later pacemaker or lead interventions including replacements or upgrades, as well as cause for intervention.

There were 4 additional neonatal patients with CHB treated at our institution during the above-noted time period. One patient with CHB was transferred to our institution on day 9 after birth in extremis. The child was supported by an oscillator ventilator and high-dose pressors. A temporary ventricular lead was placed at the bedside. The child died of anasarca and coagulopathy 2 days later. One patient in 1991, who weighed $2.9 \mathrm{~kg}$ at birth, had placement of a VVI pacemaker at 4 days of age. That patient had elective generator replacement at 5 years of age and was then lost to follow-up. There were 2 other neonates with $\mathrm{CHB}$ who were not treated with a pacemaker at birth $(1990,1991)$.

Five patients had isolated CHB with structurally normal hearts. Of this group, 1 patient's mother tested positive for Sjögren syndrome, 1 patient had a family history of lupus, and 3 patients' mothers tested negative for lupus. Four of the other 5 patients had

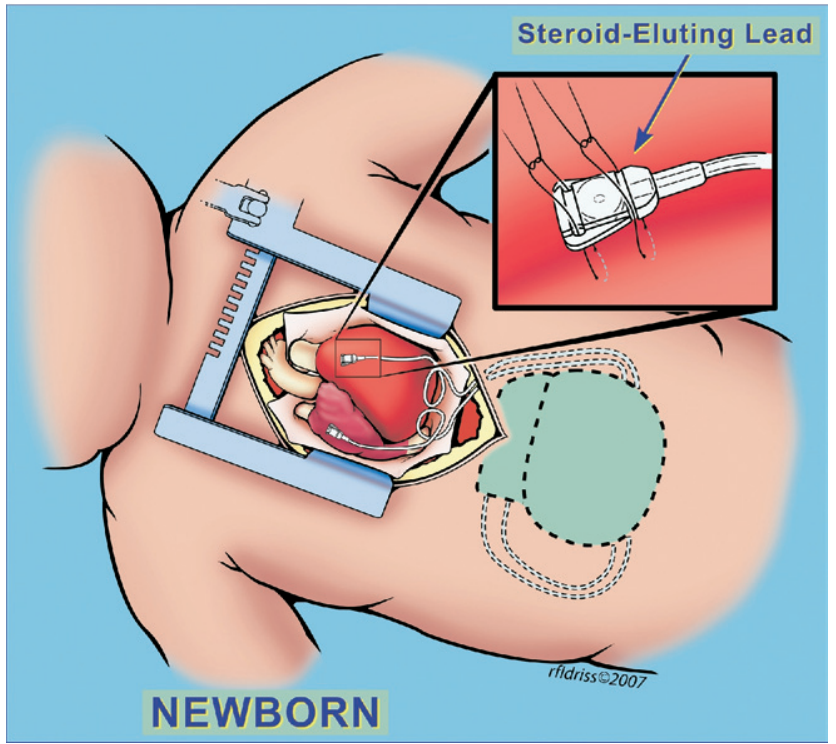

Figure 1. Dual-chamber pacing leads as placed through a full sternotomy. The steroid-eluting leads are directly affixed to the epicardium with two 5-0 polypropylene sutures.

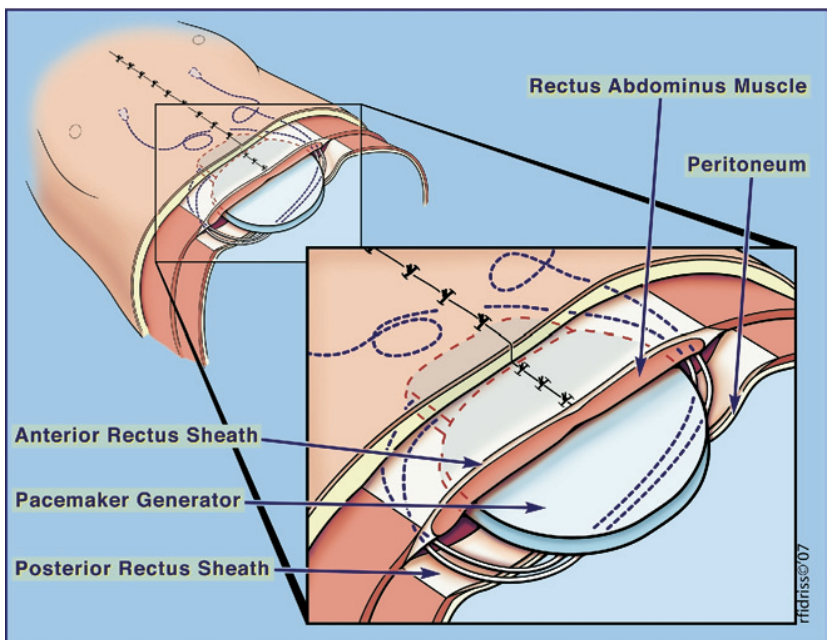

Figure 2. A pocket for the pacemaker is created beneath both rectus muscles. Through a midline incision extending nearly to the umbilicus, bilateral subcutaneous flaps are created, allowing mobilization of the anterior rectus sheath. The anterior rectus sheath is entered on either side of the linea alba. This opening is extended vertically to free up the anterior rectus sheath. Next, the rectus muscle is dissected off the posterior rectus sheath. The pacemaker is implanted just above the posterior rectus sheath. The peritoneum is not entered. The rectus muscles are reapproximated in the midline with interrupted polyglactin sutures (Vicryl; Ethicon, Inc, Johnson \& Johnson, New Brunswick, NJ), providing a muscular padding for the pacemaker. The subcutaneous layer is approximated with running polyglactin and the skin with subcuticular polydioxanone or interrupted nylon. 


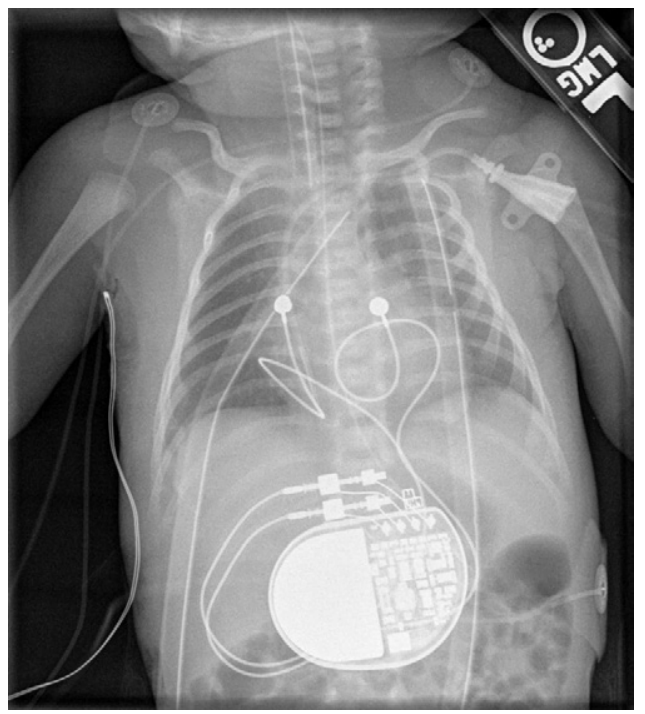

Figure 3. Babygram in a 2.2-kg infant shows the typical postoperative appearance after placement of a dual-chamber epicardial pacemaker. The left pleural space has been drained by a left chest tube. The right pleural space and mediastinum are drained by a chest tube passed through the right pleural space. The ventricular lead is on the high right ventricular outflow tract. Coils of the lead are placed within the pericardium to allow for growth. In a similar fashion, a coil is placed within the pacemaker pocket. The size of the dual-chamber pacemaker in comparison to the baby is quite evident, illustrating the need for implantation beneath both rectus muscles.

structurally abnormal hearts associated with heterotaxy syndrome (3 polysplenia, 1 asplenia). One other patient had fetal hydrops, atrial flutter, and ventricular tachycardia diagnosed in utero, with myocarditis and cardiomyopathy diagnosed postnatally.

A partial sternotomy approach was used in the first 2 patients and a full sternotomy in the last 8 patients. The first patient received two non-steroid eluting unipolar epicardial leads, Oscor model MP35V (Oscor Inc, Palm Harbor, Fla). All subsequent patients received $25-\mathrm{cm}$ steroid-eluting unipolar leads, Medtronic models 10295B (1 patient) and 4965 (8 patients) (Medtronic, Inc, Minneapolis, Minn). Each lead was sutured to the epicardial surface with two interrupted 5-0 polypropylene sutures (Figure 1). The ventricular lead was placed in the high right ventricular outflow tract. Atrial lead placement was in the midportion of the right atrium to avoid stimulation of the phrenic nerve. The pacemaker generator was placed in a submuscular bilateral rectus sheath pocket as previously reported. ${ }^{10}$ The rectus muscle and anterior rectus sheath were brought together in the midline (Figure 2 ). In the neonate, the size of the pacemaker generator prevents placement of the device under only one or the other rectus muscle (Figure 3). Various models of dual-chamber pacemaker generators were used over time, including Intermedics Cosmos II 284-05 (now Guidant Corp, Indianapolis, Ind), and Medtronic models Thera DR 7960, Thera DR 7968, Kappa DR KDR921, EnPulse DR
E1DR21, and EnPulse DR E2DR21. Successful atrioventricular synchrony was established in all patients after pacemaker placement.

Data were compared with the Fisher exact test using StatView statistical software (SAS Institute Inc, Cary, NC). Two-tailed $P$ values are reported.

\section{Results}

Successful atrioventricular synchrony was established in all patients. Excellent pacing and sensing thresholds were obtained, as illustrated in Table 1. Atrial leads had a mean P-wave sensing of $4.7 \pm 2.6 \mathrm{mV}$ with a voltage threshold of $0.8 \pm 0.3 \mathrm{~V}$. Ventricular leads had a mean R-wave sensing of $13.0 \pm 5.7 \mathrm{mV}$ with a voltage threshold of $0.9 \pm 0.5 \mathrm{~V}$. Median postoperative stay was 14 days. There were no wound complications or early lead failures. Three of the 4 patients with heterotaxy died at 3 days, 14 days, and 15 months postoperatively. The patient with cardiomyopathy died suddenly at 6 months of acute myocarditis. The clinical characteristics of the 4 patients who died are shown in Table 2. Autopsy findings were available for all deceased patients. No patients with structurally normal hearts died $(P<.05)$. Mean follow-up interval in survivors is $6.1 \pm 7.1$ years (range 0.2-16.8 years) with 1 patient lost to follow-up.

One patient with $\mathrm{CHB}$ and heterotaxy syndrome (asplenia, dextrocardia) is alive at current follow-up. At 2 days of age she had pacemaker placement via sternotomy followed immediately by coarctation repair via right thoracotomy. She underwent partial atrioventricular canal repair at 9 months of age and is doing well 10 months later.

Three of 6 surviving patients have undergone lead revision. Mean interval to first lead revision is $5.5 \pm 3.4$ years, with a range of 1.7 to 7.1 years. In all 3 cases the indication for revision was ventricular lead fracture. The same 3 patients underwent pacemaker generator change at the time of lead revision; one of these patients had also undergone a prior generator change. Mean interval to first generator change is $4.3 \pm 2.7$ years, with a range of 1.7 to 7.1 years. The patient with two generator changes, at 4 years and 7 years, has subsequently had conversion to a transvenous system at 14 years. At last follow-up, all patients remain in DDD pacing mode with atrioventricular synchrony. There has been no atrial lead failure.

\section{Discussion}

When the late Dr Farouk S. Idriss first reported our experience implanting single-lead, epicardial ventricular pacemakers for neonatal CHB in 1973, he stated that, "Pacing controlled by the atrial rate may be the solution. However, at present, these pacemakers are too cumbersome for implantation in infants." 8 Advances in pacemaker technology have led to smaller hardware and better battery life, leading to the technical feasibility of DDD pacing. The steroideluting epicardial lead developed by Medtronic was another 
TABLE 1. Patient characteristics and pacing parameters

\begin{tabular}{|c|c|c|c|c|c|c|}
\hline Patient & Diagnosis & $\begin{array}{l}\text { P wave } \\
(\mathrm{mV})\end{array}$ & $\begin{array}{c}\text { Atrial } \\
\text { threshold (V) }\end{array}$ & $\begin{array}{c}\text { R wave } \\
\text { (mV) }\end{array}$ & $\begin{array}{l}\text { Ventricular } \\
\text { threshold (V) }\end{array}$ & AS-VP/AP-VP \\
\hline 1 & Isolated CHB & 2 & 0.6 & 16.5 & 0.8 & $100 \% / 0 \%$ \\
\hline 2 & Isolated CHB & 2 & & 14 & & $96 \% / 4 \%$ \\
\hline 3 & $\begin{array}{l}\text { CHB, fetal hydrops, myocarditis, } \\
\text { cardiomyopathy }\end{array}$ & 3.6 & 0.5 & 23.4 & 0.7 & No information \\
\hline 4 & Isolated CHB & 8 & 0.5 & 11 & 1.8 & $100 \% / 0 \%$ \\
\hline 5 & Isolated CHB & 4 & & 9.8 & 0.2 & $100 \% / 0 \%$ \\
\hline 6 & $\begin{array}{l}\text { CHB, heterotaxy syndrome (polysplenia); } \\
\text { complete AVC, COA }\end{array}$ & 2.8 & 1 & 11 & 0.5 & $8 \% / 92 \%$ \\
\hline 7 & $\begin{array}{l}\text { CHB, heterotaxy syndrome (polysplenia); } \\
\text { VSD, common atrium, bilateral PDA, } \\
\text { bilateral SVC }\end{array}$ & 4 & 1.4 & 8 & 1.2 & $50 \% / 50 \%$ \\
\hline 8 & $\begin{array}{l}\text { CHB, heterotaxy syndrome (polysplenia); } \\
\text { DORV, pulmonary stenosis, ventricular } \\
\text { non-compaction }\end{array}$ & 9 & 0.6 & 5.4 & 0.7 & $99 \% / 1 \%$ \\
\hline 9 & $\begin{array}{l}\text { CHB, heterotaxy syndrome (asplenia } \\
\text { with midline liver); unbalanced AVC, } \\
\text { COA, dextrocardia }\end{array}$ & 3.5 & 0.8 & 10 & 1.3 & $0 \% / 100 \%$ \\
\hline 10 & Isolated CHB & 8 & 0.7 & 21 & 0.6 & $100 \% / 0 \%$ \\
\hline Mean \pm & & $4.7 \pm 2.6$ & $0.8 \pm 0.3$ & $13 \pm 5.7$ & $0.9 \pm 0.5$ & \\
\hline
\end{tabular}

$A P$-VP, Percentage of time pacemaker is performing atrial pacing and ventricular pacing; $A S-V P$, percentage of time pacemaker is performing atrial sensing and ventricular pacing; $A V C$, atrioventricular canal; $C H B$, congenital complete heart block; $C O A$, coarctation of the aorta; DORV, double-outlet right ventricle; $P D A$, patent ductus arteriosus; $S D$, standard deviation; $S V C$, superior vena cava; $V S D$, ventricular septal defect.

technologic leap that made dual-chamber pacing possible, particularly atrial pacing. ${ }^{9,11}$ We have implanted dualchamber epicardial pacemakers for $\mathrm{CHB}$ for the past 17 years.

Advantages of dual-chamber pacing include sinus node responsiveness and maintaining physiologic atrioventricular synchrony. Karpawich and associates ${ }^{12}$ compared physiologic response of VVI versus DDD pacing in 8 pediatric patients with nonsurgical atrioventricular block in 1987. This report showed that although both pacing modes allowed ventricular rate to increase with exercise, VVI mode was associated with ectopy and greater risk for sudden death. The study also found hemodynamic benefits of DDD pacing while at rest for patients with complete atrioventricular block. Patients in DDD mode exhibited slower resting sinus rates as well as increases in stroke volume, shortening fraction, and cardiac output compared with those exhibited with VVI pacing.

Arguments against dual-chamber epicardial pacing in neonates with $\mathrm{CHB}$ include technical difficulty and atrial lead complications. ${ }^{13,14}$ Our experience and reports of others clearly demonstrate the technical feasibility of this strat-

TABLE 2. Clinical characteristics of patients with CHB who died

\begin{tabular}{|c|c|c|c|c|c|}
\hline Patient & $\begin{array}{l}\text { Age at pacemaker } \\
\text { implantation }\end{array}$ & Diagnosis & Other Procedures & Age at death & Cause of death \\
\hline 1 & $2 d$ & $\begin{array}{l}\text { Myocarditis, cardiomyopathy, } \\
\text { ventricular tachycardia }\end{array}$ & & $6 \mathrm{mo}$ & $\begin{array}{l}\text { Sudden death, } \\
\text { acute } \\
\text { myocarditis }\end{array}$ \\
\hline 2 & $1 \mathrm{~d}$ & $\begin{array}{l}\text { Heterotaxy (polysplenia), unbalanced } \\
\text { AVC, coarctation of the aorta }\end{array}$ & $\begin{array}{l}\text { Coarctation (5 d), } \\
\text { AVC, Glenn, } 6 \text { mo }\end{array}$ & $15 \mathrm{mo}$ & $\begin{array}{l}\text { Necrotizing } \\
\text { enterocolitis }\end{array}$ \\
\hline 3 & $2 d$ & $\begin{array}{l}\text { Heterotaxy (polysplenia), VSD, ASD } \\
\text { bilateral PDA, SVC, LVOT } \\
\text { obstruction }\end{array}$ & $\begin{array}{l}\text { VSD closure, LVOT } \\
\text { tract surgery }(3 \mathrm{~d})\end{array}$ & $5 d$ & $\begin{array}{l}\text { Renal failure, } \\
\text { low cardiac } \\
\text { output }\end{array}$ \\
\hline 4 & $3 d$ & $\begin{array}{l}\text { Heterotaxy (polysplenia), DORV } \\
\text { severe PS, PDA (PGE } 1 \text { ) }\end{array}$ & $\begin{array}{l}\text { Blalock-Taussig } \\
\text { shunt }(3 \mathrm{~d})\end{array}$ & $17 \mathrm{~d}$ & $\begin{array}{l}\text { Anasarca, } \\
\text { sepsis }\end{array}$ \\
\hline
\end{tabular}

$\overline{A S D}$, Atrial septal defect; $A V C$, atrioventricular canal; $C H B$, congenital complete heart block; DORV, double-outlet right ventricle; $L V O T$, left ventricular outflow tract; $P D A$, patent ductus arteriosus; $P G E_{1}$, prostaglandin $\mathrm{E}_{1}, P S$, pulmonary stenosis; $S V C$, superior vena cava; VSD, ventricular septal defect. 
egy. ${ }^{13}$ We had no incidence of atrial lead fracture or failure in this small series. Outcomes were excellent, $100 \%$ survival, in patients with structurally normal hearts. Furthermore, all patients remain in DDD mode with atrioventricular synchrony at a mean follow-up of 6.1 years from the date of surgery.

The high mortality rate of patients with $\mathrm{CHB}$ and structurally abnormal hearts in our series (4/5 patients, $80 \%)$ is consistent with reports in the literature. ${ }^{1,6,15} \mathrm{Berg}$ and colleagues ${ }^{1}$ reported a series of 60 fetuses with CHB identified at two centers in Germany between 1989 and 2003 and one center in the United States between 1998 and 2003. Fetal hydrops was the strongest predictor of nonsurvival, followed by associated complex cardiac malformations, particularly left isomerism (polysplenia). No patient with fetal hydrops survived past the neonatal period. Taketazu and colleagues ${ }^{6}$ recently reported a series of prenatal and postnatal heterotaxy syndrome cases at The Hospital for Sick Children, Toronto, Canada, between 1992 and 2002. There were 46 continued pregnancies out of 71 diagnosed fetuses, 14 with right isomerism and 32 with left isomerism. One fetus with right isomerism and 4 with left isomerism had associated CHB; all died in utero or the neonatal period. Our team had hoped that a strategy of early dual-chamber pacing might change the natural history of these patients, but our review has shown this hypothesis not to be correct. The prognosis remains poor for neonates with $\mathrm{CHB}$ and structurally abnormal hearts, particularly heterotaxy syndrome, even with early dual-chamber pacing. These findings suggest that families should be counseled appropriately, and cardiac transplant may need to be considered soon after stabilization with a permanent (or temporary) pacemaker.

In summary, review of our surgical strategy has shown that implantation of dual-chamber epicardial pacemakers in neonates with $\mathrm{CHB}$ is technically feasible and yields a stable, long-term pacing system. This was made possible by the development of steroid-eluting epicardial leads and smaller pacemaker devices. We have had excellent outcomes and no mortality in patients with structurally normal hearts, and system longevity at 6-year follow-up is excellent. Hence, for the neonate with isolated CHB, early DDD pacing is our procedure of choice. However, neonates with CHB associated with heterotaxy syndrome appear to have a poor prognosis. In light of our findings, it seems that for neonates with $\mathrm{CHB}$ and structurally abnormal hearts, stabilization with a pacemaker may be only a temporizing procedure with early consideration given to cardiac transplantation.

\section{Addendum}

Since the submission of this article, 2 more neonates (3-day-old, $2.7 \mathrm{~kg}$ and 1-day-old, $2.5 \mathrm{~kg}$ ) have had successful placement of dual-chamber epicardial pacemakers.

\section{References}

1. Berg C, Geipel A, Kohl T, Breuer J, Germer U, Krapp M, et al. Atrioventricular block detected in fetal life: associated anomalies and potential prognostic markers. Ultrasound Obstet Gynecol. 2005;26: 4-15.

2. Villain E, Coastedoat-Chalumeau N, Marijon E, Boudjemline Y, Piette JC, Bonnet D. Presentation and prognosis of complete atrioventricular block in childhood, according to maternal antibody status. J Am Coll Cardiol. 2006;48:1682-7.

3. Jayaprasad N, Johnson F, Venugopal K. Congenital complete heart block and maternal connective tissue disease. Int J Cardiol. 2006;112: 153-8.

4. Jaeggi ET, Hamilton RM, Silverman ED, Zamora SA, Hornberger LK Outcome of children with fetal, neonatal or childhood diagnosis of isolated congenital atrioventricular block. A single institution's experience of 30 years. $J$ Am Coll Cardiol. 2002;39:130-7.

5. Breur JM, Udink Ten Cate FE, Kapusta L, Cohen MI, Crosson JE, Boramanand $\mathrm{N}$, et al. Pacemaker therapy in isolated congenital complete atrioventricular block. Pacing Clin Electrophysiol. 2002; 25:1685-91.

6. Taketazu M, Lougheed J, Yoo SJ, Lim JS, Hornberger LK. Spectrum of cardiovascular disease, accuracy of diagnosis, and outcome in fetal heterotaxy syndrome. Am J Cardiol. 2006;97:720-4.

7. Moak JP, Barron KS, Hougen TJ, Wiles HB, Balaji S, Seeram N, et al. Congenital heart block: development of late-onset cardiomyopathy, a previously underappreciated sequela. J Am Coll Cardiol. 2001;37: $238-42$.

8. Idriss FS, Otto R, Nikaido[h] H, Newfeld E, Paul MH. Implantation of permanent pacemaker in the first month of life for congenital complete heart block. J Thorac Cardiovasc Surg. 1973;65:851-5.

9. Dodge-Khatami A, Johnsrude CL, Backer CL, Deal BJ, Strasberger J, Mavroudis C. A comparison of steroid-eluting epicardial versus transvenous pacing leads in children. J Card Surg. 2000;15:323-9.

10. DeLeon SY, Ilbawi MN, Idriss FS. Pacemaker implantation in infants and children: a simplified approach. Ann Thorac Surg. 1980;30:599601.

11. Stokes KB. Preliminary studies on a new steroid eluting epicardial electrode. Pacing Clin Electrophysiol. 1988;11:1797-803.

12. Karpawich PP, Perry BL, Farooki ZQ, Clapp SK, Jackson WL, Cicalese CA, et al. Pacing in children and young adults with nonsurgical atrioventricular block: comparison of single-rate ventricular and dual-chamber modes. Am Heart J. 1987;113:316-21.

13. Villain E, Martelli H, Bonnet D, Iserin L, Butera G, Kachaner J. Characteristics and results of epicardial pacing in neonates and infants. Pacing Clin Electrophysiol. 2000;23:2052-6.

14. Horenstein MS, Karpawich PP. Pacemaker syndrome in the young: do children need dual chamber as the initial pacing mode? Pacing Clin Electrophysiol. 2004;27:600-5.

15. Jaeggi ET, Hornberger LK, Smallhorn JF, Fouron JC. Prenatal diagnosis of complete atrioventricular block associated with structura heart disease: combined experience of two tertiary care centers and review of the literature. Ultrasound Obstet Gynecol. 2005;26:16-21. 